\title{
Succession planning in Uganda: Early outreach for AIDS-affected children and their families
}

Horizons Program

Makerere University Department of Sociology

Plan Uganda

Follow this and additional works at: https://knowledgecommons.popcouncil.org/departments_sbsr-hiv

Part of the Demography, Population, and Ecology Commons, Health Policy Commons, Immune System Diseases Commons, International Public Health Commons, Maternal and Child Health Commons, Medicine and Health Commons, Public Health Education and Promotion Commons, Virus Diseases Commons, and the Women's Health Commons How does access to this work benefit you? Let us know!

\section{Recommended Citation}

Horizons Program, Makerere University Department of Sociology, and Plan Uganda. 2004. "Succession planning in Uganda: Early outreach for AIDS-affected children and their families," Horizons Final Report. Washington, DC: Population Council. 


\section{Horizons $\Lambda$}

Succession Planning in Uganda: Early Outreach for AIDS-affected Children and Their Families

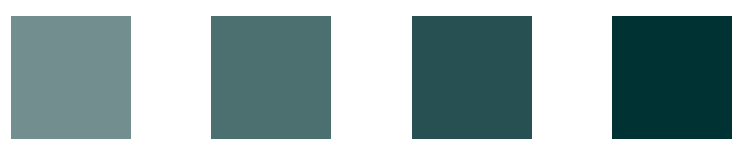

Horizons Program

Makerere University,

Department of Sociology

Plan/Uganda 
Succession Planning in Uganda: Early Outreach for AI DS-affected Children and Their Families

\author{
Horizons \\ Makerere University Department of Sociology \\ Plan/Uganda
}




\section{Acknowledgments}

The research team at Makerere University, Department of Sociology, included Rebecca Nyonyintono, coprincipal investigator; Gabriel Jaggwe-Wadda and Robert Kabumbuli, research coordinators; Fred Bateganya, who carried out the qualitative research with HIV-positive parents; and Stephen Boogere, who started as a research assistant but went on to make himself invaluable in all aspects of the project, from administration and logistics to carrying out in-depth interviews. Laelia Gilborn of Horizons/ Population Council, served as co-principal investigator and prepared this report.

The research team is indebted to wonderful friends and colleagues at Plan/Uganda, the Diocese of Luwero, Grasslands, and the National Community of Women Living with AIDS (NACWOLA) for their ongoing commitment to this research, while carrying out groundbreaking programs for AIDS-affected families in Uganda. Counseling aides in Luwero and Tororo always welcomed us, led us to the research participants, and shared their insights about the study communities and programs. This study would not have been possible without their continuing collaboration.

The team is also grateful to Scott Geibel, Roberto Valverde, and Jotham Mubangizi for data management and analysis; Carolyn Baek, Katie Schenk, and Ellen Weiss for technical review and editing; and to Elise Ayers, Rebecca Bunnell, Edward Kirumira, and Naomi Rutenberg for ongoing technical support and guidance. We also very much appreciate the wisdom and dedication of our Advisory Committee, which guided us throughout the course of the study.

Most of all, we are grateful to the study communities who welcomed us three years in a row, and to the research participants for sharing their valuable time and personal stories with us. It is our sincere hope that this research will result in improved programs for AIDS-affected families in the study communities and beyond.

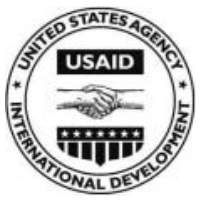

This research was supported by the Horizons Program, which is implemented by the Population Council in collaboration with the International Center for Research on Women, International HIV/AIDS Alliance, Program for Appropriate Technology in Health, Tulane University, Family Health International, and Johns Hopkins University. Horizons is funded by the U.S. Agency for International Development, under the terms of HRN-A-00-97-00012-00 The opinions expressed herein are those of the authors and do not necessarily reflect the views of the U.S. Agency for International Development.

Published in December 2004.

\section{Population Council}

The Population Council is an international, nonprofit, nongovernmental institution that seeks to improve the well-being and reproductive health of current and future generations around the world and to help achieve a humane, equitable and sustainable balance between people and

resources. The Council conducts biomedical, social science, and public health research and helps build research capacities in developing countries. Established in 1952, the Council is governed by an international board of trustees. Its New York headquarters supports a global network of regional and country offices.

Copyright $\odot 2004$ The Population Council Inc.

This document may be reproduced in whole or in part without permission of the Population Council provided full source citation is given and the reproduction is not for commercial purposes.

Suggested citation: Horizons, Makerere University Department of Sociology, Plan/Uganda. 2004. "Succession planning in Uganda: Early outreach for AIDS-affected children and their families,” Horizons Final Report. Washington, DC: Population Council. 


\section{Table of Contents}

\section{Executive Summary}

Introduction 4

The impact of HIV/AIDS on children 4

Program responses to children affected by AIDS in Africa 5

Study Methods $\quad 7$

$\begin{array}{ll}\text { Study goal and objectives } & 7\end{array}$

$\begin{array}{ll}\text { The succession planning program } & 7\end{array}$

Study design $\quad 9$

Selection and description of study participants $\quad 9$

Data collection 10

Data analysis $\quad 10$

$\begin{array}{ll}\text { Limitations of the study } & 12\end{array}$

Results: I mpact of Succession Planning $\quad 14$

$\begin{array}{ll}\text { Program impact on HIV-positive parents } & 14\end{array}$

Program impact on standby guardians $\quad 28$

What about the children? 33

Discussion of Results

Program and Policy Recommendations 37

$\begin{array}{ll}\text { Program and policy implications } & 37\end{array}$

An update from the field 39

$\begin{array}{ll}\text { Utilization of research results } & 40\end{array}$

References $\quad 41$ 



\section{Executive Summary}

This publication reports on an intervention study that evaluated the effectiveness of a succession planning (SP) program in Uganda. Unlike most other programs for AIDS-affected children, succession planning reaches children and their families while their HIV-positive parents are still living and in a position to plan for their children's long-term well-being.

The focus of this report is on the impact of the SP intervention on HIV-positive parents' and standby guardians' efforts to prepare for the future of children who will experience parental loss. The report also presents findings on the impact of the program on children and discusses the program and policy implications of the research. ${ }^{1}$

The succession planning program was implemented by Plan/Uganda, Grasslands (Tororo), and the National Community of Women Living with AIDS (NACWOLA, Luwero), while the research was carried out by the Department of Sociology at Makerere University (Kampala) and the Horizons Program. To assess program impact, researchers conducted structured interviews with HIVpositive parents, standby guardians, and children who were and were not exposed to succession planning at baseline (1999) and two years later (2001).

\section{Key Findings}

\section{Succession planning was associated with a significant increase in the proportion of parents who appointed a guardian.}

Nearly half (47 percent) of HIV-positive parents had not appointed a guardian at baseline. Reasons given for not having a standby guardian included the following: not knowing anyone willing or able to be a guardian, still being in good health themselves, and not wanting to reveal their serostatus to a potential guardian. Implementers of the SP program reported, however, that parents responded very positively to encouragement and support for appointing guardians. Indeed, there was a significant increase over the two-year period, from 56 to 81 percent ( $\mathrm{p}<0.05$ ), in the proportion of parents exposed to succession planning who had appointed a standby guardian.

\section{Will writing doubled among parents in succession planning, but still only one in five parents had written wills.}

Baseline findings showed that fears about and experiences with property grabbing were widespread, but that few parents had taken steps to ensure that their property would be passed on to their children. The proportion of parents with written wills in the SP area more than doubled from 9 percent to 20 percent, yet the same pattern was found among comparison parents, making it

\footnotetext{
${ }^{1}$ For a discussion of baseline findings, see Gilborn et al. 2001.
} 


\section{Hgrizons}

impossible to prove program effects. This was one of the most challenging components of succession planning in the Ugandan context due to taboos about writing wills, low literacy, and other factors. Nevertheless, the demand for assistance with wills and legal matters grew among HIV-positive parents, suggesting that the approach is feasible and acceptable.

\section{After two years in the SP program, parents were significantly more likely to have disclosed their positive serostatus to at least one child.}

At baseline, most older children wanted their parents to "tell them the truth" about being HIVpositive because they wanted to know the truth, avoid HIV/AIDS, know what to do when the parent dies, prepare for the parent's death, and discuss guardians and wills. While only 51 percent of parents in SP had disclosed at baseline, 75 percent had done so two years later. This increase in parent-to-child communication fulfills an important need for open discussion, as expressed by older children of HIV-positive parents. Nevertheless, disclosure can be upsetting and may not be appropriate for younger children, so it must be handled with sensitivity.

Planning for the future is a process that can stir many emotions, so parents require sensitive, reliable program support.

Appointing guardians, disclosing serostatus, and writing a will are all steps that a parent can take to reduce fears and uncertainty about the future and ensure long-term well-being for children. These actions are also, however, emotionally, culturally, and logistically complex. Families engaging in this process require strong, ongoing program support.

\section{Standby guardians appointed by parents are predominantly male, but it is women who ultimately assume much of the responsibility for orphaned children.}

It was more difficult than expected to reach and engage standby guardians in the SP program. Not all parents were able to find an appropriate standby guardian, and others had appointed someone living far away. Thus, relatively few standby guardians were available to participate in the program. The characteristics of standby guardians were also different from individuals currently serving as guardians. For example, 57 percent of the parents in the baseline survey who had appointed a standby guardian chose a male. Yet 63 percent of current guardians (i.e., already caring for orphan children) who were interviewed at baseline were female. This suggests that the people appointed as standby guardians are not necessarily the individuals who ultimately care for the children once the parents die. 
Succession planning is an attractive and effective program for HIV-positive parents who wish to ensure a better future for their children, but it is challenging to implement.

Overall, the SP program met with a high degree of acceptability and enthusiasm among HIVpositive parents, who generally welcomed the support to ensure a better future for their children. Indeed, as word spread about the program, there was demand for it in neighboring areas. However, $\mathrm{SP}$ is a complex program made up of many components, including counseling and support to parents as they disclose their HIV-status to children and others, legal training and assistance with wills, and income-generation activities. As such, it must be implemented by an organization or a group of organizations with a wide range of technical proficiencies.

\section{More research is needed to explore the long-term impact of succession planning on children once their parents have died.}

Succession planning did not appear to have a pronounced effect on children whose parents were still living. This is not surprising, given that several of the program components focused on the long-term well-being of children. Steps taken by parents in the program (disclosing serostatus, appointing guardians, and writing wills) are promising, and suggest that SP does contribute to helping parents plan for a better future for their children. But more research is needed to document longer-term program impact. 


\section{Hgrizons}

\section{Introduction}

\section{The I mpact of HIV/ AI DS on Children}

At the end of 2001, there were over 13.4 million children orphaned by HIV/AIDS in the world, with "orphan" defined as a child under the age of 15 who has lost one or both parents-in this case due to HIV/AIDS. Over 11 million of these were in Africa. The global figures are estimated to grow to 25 million by 2010 (UNAIDS/UNICEF/USAID 2002).

In the year 2001, approximately 15 percent of all children under the age of 15 in Uganda were orphans. About half, or roughly 884,000 of these children, were orphaned by HIV/AIDS specifically (UNAIDS/UNICEF/USAID 2002). In the same year, taking into account youth between the ages of 15 and 17, the Uganda Bureau of Statistics and others estimated that there were more than 2 million orphaned children and youth under the age of 18 in the country. The crisis is so extensive that approximately 25 percent of households in Uganda house at least one orphan. These households have higher dependency ratios than other households, with an average of two extra dependents (Wakhweya et al. 2002).

Children orphaned by AIDS are vulnerable in almost all aspects of their lives (Haworth and Kalumba 1991; Foster et al. 1995; Foster et al. 1997). Invariably, orphans witness the prolonged illness and death of one or more family members and suffer mental distress as a result. Some of the many challenges faced by orphans are loss of family, depression, increased malnutrition, lack of immunization and health care, lack of schooling, early entry into paid or unpaid labor, loss of inheritance through "property grabbing," homelessness, early marriage, exposure to abuse, and increased risk of HIV/AIDS (Hunter and Williamson 1997).

Research in Kampala, Uganda, revealed that 47 percent of households with orphans found it difficult to pay school fees, compared to only 10 percent of households without orphans (Muller and Abbas 1990). A 1996 study found that the main problems among Ugandan orphans were inadequate shelter; inability to pay for school fees and supplies; lack of bedding, clothing and medical care; and the burden of having to care for younger siblings (Shuey et al. 1996). Research in Tanzania (Ainsworth and Semali 2000) and Kenya (Lindblade 2003) found higher rates of malnutrition in orphans compared to non-orphans. A 20-country review by UNICEF showed that double orphans (both parents had died) had lower school enrollment than non-orphans (ages 10 to 14) in every country (UNICEF 2000). Another study in Uganda suggests that orphans are at high risk of contracting HIV/AIDS and that female orphans are more at risk of infection than any other group in the population (personal communication, Dr. Gimono Wamai, April 1999).

The problems encountered by AIDS-affected children start before their parents die. Most children orphaned by in Uganda are single orphans, living with their surviving parent (predominantly female) after the first parent dies. In one study, 75 percent of widowed parents surveyed found it "very difficult" to support their families. Most often, the parents reported insufficient food, clothing and bedding, financial resources, health care, and funds for school fees. They also found 
that 22 percent of female widows had experienced property grabbing or mismanagement of their property by relatives after their spouse died (Wakhweya et al. 2002). Despite recent advances in laws protecting women's property rights, patriarchal inheritance practices continue to undermine the economic and social well-being of widows and children.

HIV-positive parents experience psychosocial distress because of uncertainty about their children's future. Children also experience psychosocial distress about their future, which may be manifested by depression or behavioral problems at school (Hunter and Williamson 1997). It is likely that psychosocial distress among both HIV-positive parents and their children can be reduced by making provisions and plans for the children once orphaned (AHRTAG 1997).

The well-being of all children affected by AIDS depends in great part on the capacity of the community to support and raise them. Hunter and Williamson (1997) state: "The first and most important responses to the problems caused by HIV/AIDS come from the affected children, families, and communities themselves. The efforts of governments, NGOs, and donors are significant largely to the extent that they help children, families, and communities cope more easily with these problems." Yet few programs have focused on preparing and supporting willing guardians to take on additional child-care responsibilities.

Most African cultures are characterized by strong family and kinship networks that function as social support systems in times of need. Within this system, children who lose their parents are typically taken in by a relative, such as an uncle or aunt, as has been the pattern in East Africa. However, as the prevalence of HIV increases and the number of orphans grows, this system is being challenged. Although most experts do not believe that the African family structure has "collapsed" under the weight of AIDS, there is no doubt that caregivers are increasingly burdened. Some adults refuse to take in orphans, while others continue to take them in despite their own poverty, advanced age, or ill health; cases of uncles or grandmothers inheriting several orphans are commonplace. Increasingly, orphans find themselves belonging to a household headed by an elderly grandparent with no source of income, or by an older sibling under the age of 18.

\section{Program Responses to Children Affected by AI DS in Africa}

In response to the difficulties that orphans face, many organizations and programs are providing services and support to AIDS-orphaned children in East and Southern Africa. Typical program components include providing school fees and supplies, supplementary feeding, home visits by community members who assist affected children, and vocational training. Few of these programs have been evaluated formally for impact. Even fewer of these programs reach children until after both parents have died, when in fact the impact of parental HIV infection starts much earlier.

According to Hunter and Williamson (1997), "Interventions to respond to AIDS orphans should therefore include all children affected by HIV/AIDS, not just those whose parents have died from AIDS." A 1999 UNAIDS publication states, "If organizations wait until children become orphans, it is almost too late." Indeed, a 1993 review of programs to reach AIDS-orphaned children in East and Southern Africa concluded that there was an urgent need to reach these children as soon as the 


\section{Hgrizons}

parent is known or suspected to be terminally ill (Reid 1993). Relatively few programs, however, have instituted this approach.

The focus of this report is on an intervention called succession planning, which does just that: reaches AIDS-affected children and their families with services before the parents die, in an effort to ensure a better future for the children. 


\section{Study Methods}

\section{Study Goal and Objectives}

The overall goal of the study was to examine the effectiveness of two programs for AIDS-affected children. These programs were succession planning (SP), which reaches children before parental death, and orphan support (OS), which reaches children after parental death.

This report focuses specifically on the effectiveness of succession planning and on the following research objectives:

- To explore the acceptability of an SP program in the Ugandan context.

- To determine the impact of SP on the actions taken by parents and standby guardians to plan and provide for AIDS-affected children.

- To assess the impact of SP on child well-being.

\section{The Succession Planning Program}

Although the impact of parental HIV infection on children starts long before a child becomes an orphan, most programs for AIDS-affected children target orphans who have already lost both parents. Succession planning intervenes earlier by working with HIV-positive parents and standby guardians when they are still in a position to plan for their children's future.

The SP program assessed in this study was implemented by the Ugandan office of Plan, an international NGO, and two local NGOs: the National Community of Women Living with AIDS (NACWOLA) in Luwero, and Grasslands in Tororo. The Horizons Program and Makerere University worked in collaboration with Plan to evaluate the succession planning program as well as ongoing orphan support in the Luwero and Tororo districts of Uganda, largely rural districts with small urban and peri-urban populations. The orphan support program was broadly similar to typical programs, providing educational, health, nutritional assistance, and other services to orphans.

Succession planning primarily targets HIV-positive parents, their children, and their standby guardians. The objective of the program is to support and encourage HIV-positive parents and appointed or standby guardians to take steps to ensure the best possible future for the children and to reduce uncertainty and fear among adults and children alike about the children's future wellbeing. Table 1 describes the program components for HIV-positive parents, their children, standby guardians, and the community. 


\section{Hgrizons}

Table 1 Succession planning target groups and program components

\begin{tabular}{ll}
\hline HIV-positive parents & $\begin{array}{l}\text { Counseling on disclosure to children } \\
\text { Creation of "memory books" } \\
\text { Legal literacy and will writing } \\
\text { Support in appointing standby guardians } \\
\text { Agriculture training, income generation, seed money }\end{array}$ \\
\hline Their children & Support for school fees and supplies, vocational training \\
\hline Standby guardians & Training in guardianship and needs of orphans \\
\hline Community & Community sensitization on AIDS-affected children
\end{tabular}

Succession planning can be viewed as a part of a continuum of care for AIDS-affected children when followed by orphan support, which reaches children who are already orphaned and living with a guardian. Components of OS programs include health care services, school fees and supplies, and health and sex education for orphans; vocational/agricultural training for older orphans; seed money and income-generation training for guardians and older orphans; training of guardians; and community sensitization about the special needs of orphans. Succession planning and orphan support are thus complementary programs reaching children and families at different stages (see Figure 1).

Figure 1 Continuum of care for AIDS-affected children

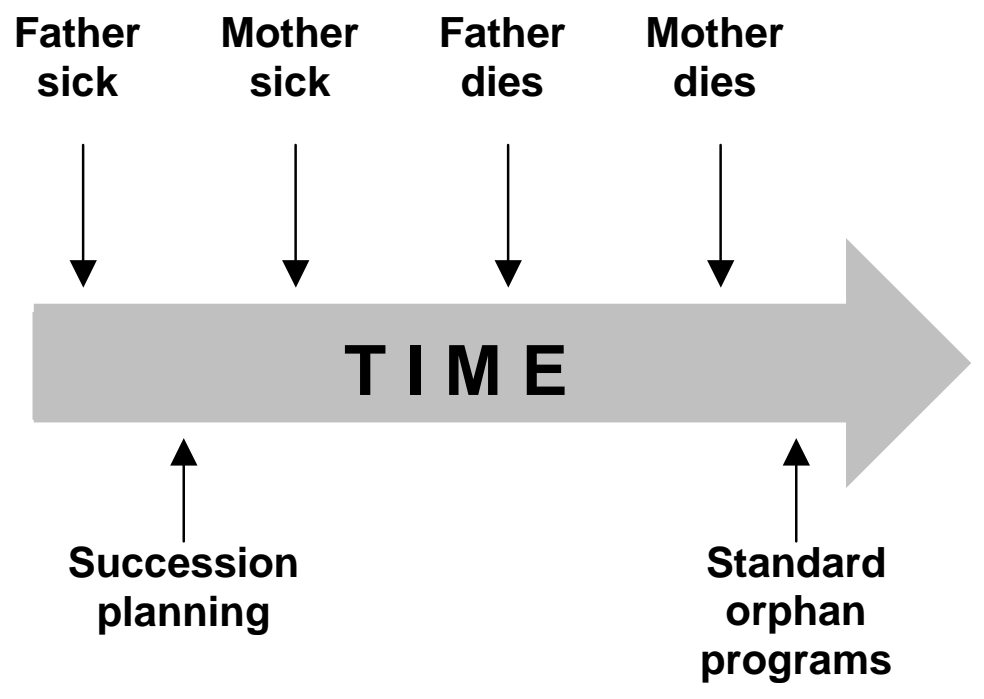




\section{Study Design}

This quasi-experimental study was carried out in the Luwero and Tororo districts of Uganda and consisted of three cross-sectional surveys conducted at annual intervals, in 1999, 2000, and 2001. There were three study arms: a control arm, a succession planning arm, and an orphan support arm. (Each district was divided into three study arms; data from the two districts were combined for analysis, so that the combined data for each study arm included respondents from both Luwero and Tororo.) Plan/Uganda continued to offer preexisting voluntary counseling and testing, post-test clubs, and home-based care services for people living with HIV and AIDS (PLHA) in all arms throughout the study, services that had been in place since 1992.

As shown in Figure 2, the control group was dropped from the study after the second observation to allow Plan and other local organizations to begin offering services to AIDS-affected children and their families. This had implications for the impact analysis, as discussed below. This report describes the effect of succession planning and draws on a subset of data from households at the first and final observations (1999 and 2001).

\section{Figure 2 Study design and timeline}

\begin{tabular}{lllll|}
\hline TIME & & & & \\
Site & $\begin{array}{l}1999 \\
\text { Baseline }\end{array}$ & $\begin{array}{l}1999 / 2000 \\
\text { Interventions }\end{array}$ & $\begin{array}{l}\text { 2000 } \\
\text { Observations while } \\
\text { interventions continued }\end{array}$ \\
\hline Control & Obs 1 & Existing & Obs 2 & ----- \\
Exp SP & Obs 1 & Existing + SP & Obs 2 & Obs 3 \\
Exp OS & Obs 1 & Existing + OS & Obs 2 & Obs 3 \\
\hline
\end{tabular}

\section{Selection and Description of Study Participants}

Two kinds of households were recruited in each study arm and at each observation: households headed by an HIV-positive parent (PLHA households) and households with an orphan and guardian pair (orphan households). However, succession planning was offered only in the SP arm and only to the PLHA households. Similarly, orphan support was offered only in the OS arm and only to orphan households.

For the baseline observation, PLHA households were identified by contacting current adult clients of preexisting home-based care services. This same list was later used to recruit participants into the succession planning intervention itself. Thus, in the second and third observations, study participants were recruited from the SP client list in the SP arm and from the home-based care client lists for the other two arms. True random sampling could not be applied because of the geographical distance between clients and the fact that Plan counseling aides had to guide 


\section{Hgrizons}

researchers to clients. Instead, the researchers attempted to recruit all households on the client lists. The vast majority of eligible households agreed to participate in the study.

Only households with children between the ages of 5 and 19 were eligible for the research. Up to four respondents were recruited in each PLHA household, including an HIV-positive parent, a younger child (ages 5 to 12), an older child (ages 13 to 19), and a standby guardian. Researchers first contacted parents and asked them to name up to two children who would participate in the study (one in each age category). Thus, selection of children in households with multiple eligible children was not random but depended upon the parent's decision. Data were collected on school holidays, so this procedure should not have biased selection in favor of out-of-school children.

Parents were also asked to identify a standby guardian - the person most likely to care for the children in the future. Only small samples of standby guardians could be reached, mainly because some parents did not identify a standby guardian and because many of those identified lived too far from the study site to be reached. Only about a third of standby guardians identified by parents were reached for an interview at each round of data collection.

\section{Data Collection}

College graduates from Makerere University Department of Sociology collected quantitative data through semi-structured interviews. These interviews took 45 minutes to an hour and were conducted in or near the participants' house with as much privacy as possible. Parents supplied the data for younger children (ages 5 to 12), while older children (ages 13 to 17) were interviewed directly.

Researchers also collected qualitative data after the first and third observations in the intervention areas. Both program implementers and beneficiaries were included in this qualitative work (see Table 2).

Table 2 Qualitative data collected from participants in succession planning

\begin{tabular}{lllll}
\hline Respondent & Method & N & Year & Topic \\
\hline $\begin{array}{l}\text { Counseling } \\
\text { aides }\end{array}$ & $\begin{array}{l}\text { In-depth } \\
\text { Interviews }\end{array}$ & 11 & 2000 & $\begin{array}{l}\text { Successes and challenges implementing SP. } \\
\text { Acceptability and impact of SP. }\end{array}$ \\
Parents & $\begin{array}{l}\text { In-depth } \\
\text { Interviews }\end{array}$ & 16 & 2002 & $\begin{array}{l}\text { Experiences and views of parent-to-child } \\
\text { disclosure of parental HIV status. }\end{array}$ \\
Parents & $\begin{array}{l}\text { Focus groups } \\
\text { (12) }\end{array}$ & 101 & 2002 & $\begin{array}{l}\text { Traditional inheritance practices. } \\
\text { Experiences and views of will writing. }\end{array}$
\end{tabular}




\section{Data Analysis}

As noted previously, for the purpose of this analysis, the authors used data from PLHA households in Rounds 1 (1999) and 3 (2001) only. These two rounds represent the baseline (1999) and the final post-intervention (2001) round. Because the control group was not included in data collection at Round 3, it was omitted from the current analysis. Thus, to assess impact of succession planning on PLHA households, researchers compared PLHA households in the SP arm (experimental group) with those in the OS arm (comparison group). (PLHA households in the OS arm were not receiving services because they are not eligible for OS.)

This report is thus based on data analysis from a sub-sample of parents, standby guardians, and older children. A total of 266 parents, 84 standby guardians, and 142 older children were interviewed in the two study groups combined at baseline, and 280 parents, 74 standby guardians, and 145 older children were interviewed in Round 3 in 2001 (see Table 3).

Table 3 Sample analyzed for this report

\begin{tabular}{lcccc}
\hline Participants & \multicolumn{2}{c}{ Baseline (1999) } & \multicolumn{2}{c}{ Follow-up (2001) } \\
& $\begin{array}{c}\text { Succession } \\
\text { planning } \\
\text { group }\end{array}$ & $\begin{array}{c}\text { Comparison } \\
\text { group }\end{array}$ & $\begin{array}{c}\text { Succession } \\
\text { planning } \\
\text { group }\end{array}$ & $\begin{array}{c}\text { Comparison } \\
\text { group }\end{array}$ \\
\hline $\begin{array}{l}\text { HIV-positive } \\
\text { parents }\end{array}$ & $\begin{array}{c}\mathrm{n}=163 \\
(72 \% \text { female })\end{array}$ & $\begin{array}{c}\mathrm{n}=103 \\
(79 \% \text { female })\end{array}$ & $\begin{array}{c}\mathrm{n}=162 \\
(82 \% \text { female })\end{array}$ & $\begin{array}{c}\mathrm{n}=118 \\
(86 \% \text { female })\end{array}$ \\
$\begin{array}{l}\text { Standby } \\
\text { guardians }\end{array}$ & $\mathrm{n}=56$ & $\mathrm{n}=28$ & $\mathrm{n}=54$ & $\mathrm{n}=20$ \\
$\begin{array}{l}\text { Older } \\
\text { children }\end{array}$ & $\begin{array}{l}\mathrm{n}=89 \\
13-19 \text { yemale })\end{array}$ & $(50 \%$ female $)$ & $(41 \%$ female $)$ & $(30 \%$ female $)$ \\
& $(44 \%$ female $)$ & $(57 \%$ female $)$ & $(48 \%$ female $)$ & $(41 \%$ female $)$ \\
\end{tabular}

Many steps were taken to analyze and interpret the results. Survey data were analyzed in SPSS. Baseline analysis consisted mostly of frequencies and cross-tabulations. To determine the significance of the difference in characteristics between different types of research participants (e.g., children of PLHA versus orphans), the researchers conducted cross tabulations and analyses using Chi square or Fisher's Exact test. A p-value of less than 0.05 was used as the threshold for significance.

Steps taken for impact analysis were as follows. Key outcomes for each type of respondent were identified at the beginning of the study. For each key outcome, a set of four cross tabulations was run: two cross tabs at the particular round (to compare SP against the comparison group at a given time) and two pre- vs. post-intervention cross tabs (to analyze difference over time for each study 


\section{Hgrizons}

group). Thus all at-round and all within-study-group differences were considered to get a complete picture of program effects.

Multivariate logistic regression analysis was then used for each key outcome in which a significant difference between groups was found, to distinguish between program effects and other factors that might affect the outcomes.

In addition, a measure of program success called the Effectiveness Index (EI) was used. This method for measuring change has been used in communications research by Hovland and associates (1949) and in family planning research by Bang (1968) and by Lawrence Green and associates (1972). This measure involves comparing the actual change in a given outcome from baseline (P1) to follow-up (P2) to potential change (100-P1). The EI is thus computed as follows:

$$
\mathrm{EI}=[(\mathrm{P} 2-\mathrm{P} 1) /(100-\mathrm{P} 1)] * 100
$$

The numerator represents actual change, while the denominator represents the maximum change that could occur. Because the sampling distribution for this statistic is not known, there is no way to test the significance of differences between EIs in two groups. The EI is useful in comparing program effects in two groups of similar size and with similar baseline prevalence of a desired program outcome, in which a larger EI suggests a larger program effect.

Finally, data interpretation meetings in the study communities and at the national level assisted researchers in interpreting the quantitative results. Meetings were conducted in each study district after the first and third (final) observations. Counseling aides and other staff of implementing NGOs attended these meetings. National dissemination meetings were held in Kampala, Uganda, after the first observation (July 2000) and the third observation (November 2002). Ministry officials, academics, local and international NGOs, donors, program managers, and press attended these national meetings.

\section{Limitations of the Study}

- The true control group was dropped after the second observation to allow services to begin in those communities. Parents and standby guardians in the orphan support areas were thus used as a comparison group in the analysis, despite the fact that there were new interventions in their communities that may have affected outcomes.

- SP and comparison parents were demographically equivalent. However, they unexpectedly started out in different places with respect to a number of key outcomes and are thus not ideal groups for comparison. (Using the Effectiveness Index helps to overcome this limitation.)

- According to program implementers, there was considerable spillover of ideas and information about the SP intervention into the geographic areas from which the comparison group was drawn, which may explain parallel changes in some outcomes in both groups of parents. 
- Only a minority of standby guardians could be reached for interview; thus, they are not a representative group of guardians. In addition, the small sample size precluded finding statistically significant changes and differences in most cases.

- The succession planning program was implemented in two different districts. Different local NGOs implemented the activities in each district, naturally leading to some variability in the intensity and nature of activities. Like all pilot programs, this one met with some delays and growing pains along the way. Overall, the SP program was less intensive than anticipated, and therefore the findings may not represent the true potential of the intervention. 


\section{Hgrizons}

\section{Results: Impact of Succession Planning}

\section{Program I mpact on HIV-Positive Parents}

\section{Profile of the parents}

Most parents were from the Ganda, Ateso, and Japadhola ethnic groups. Most were Protestant or Catholic, with a smaller percentage of Muslims, Pentecostals, and Seventh Day Adventists. Luganda was the most commonly spoken language, followed by Dopadhola, Ateso, and Swahili. Most parents earned their income from farming, brewing, or trading. Almost all had access to at least small plots of land and grew crops.

The HIV-positive parents in the study were predominantly female and predominantly widowed, reflecting the demographics of AIDS-affected households in the study areas (Monk 2000). The proportion of parents who were widowed in the two study groups combined rose from 66 percent to 79 percent between 1999 and 2001.

It should also be noted that in 2001 nearly half of these predominantly widowed HIV-positive parents were looking after not only their own children but also raising additional orphaned children. The fact that HIV-positive parents are so commonly taking in orphans, despite their illness, is an indication that the social safety net for children is truly stretched. This phenomenon was not anticipated in the SP program and must be addressed. 
Table 4 Demographic characteristics of parents

\begin{tabular}{|c|c|c|c|c|}
\hline & \multicolumn{2}{|c|}{ Baseline (1999) } & \multicolumn{2}{|c|}{ Follow-up (2001) } \\
\hline & $\begin{array}{c}\text { Succession } \\
\text { planning } \\
\text { group } \\
(n=163)\end{array}$ & $\begin{array}{c}\text { Comparison } \\
\text { group } \\
(n=103)\end{array}$ & $\begin{array}{l}\text { Succession } \\
\text { planning } \\
\text { group } \\
(\mathbf{n}=162)\end{array}$ & $\begin{array}{c}\text { Comparison } \\
\text { group } \\
(n=118)\end{array}$ \\
\hline Female (\%) & $72 \%$ & $79 \%$ & $82 \%$ & $86 \%$ \\
\hline $\begin{array}{l}\text { Average age (years) } \\
\text { [Age range] }\end{array}$ & $38[22-66]$ & 36 [21-69] & 37 [24-58] & $\begin{array}{l}38[21-59] \\
13 \text { missing }\end{array}$ \\
\hline \multicolumn{5}{|l|}{ Marital status (\%) } \\
\hline Married & $25 \%$ & $22 \%$ & $15 \%$ & $14 \%$ \\
\hline Widowed & $65 \%$ & $68 \%$ & $78 \%$ & $80 \%$ \\
\hline $\begin{array}{l}\text { Separated or } \\
\text { never married }\end{array}$ & $11 \%$ & $10 \%$ & $7 \%$ & $7 \%$ \\
\hline $\begin{array}{l}\text { Already caring for } \\
\text { orphans }(\%)\end{array}$ & $44 \%$ & $36 \%$ & $48 \%$ & $49 \%$ \\
\hline $\begin{array}{l}\text { Average years known } \\
\text { HIV status [range] }\end{array}$ & $3.1[1-12]$ & $2.9[1-14]$ & $4.5[1-10]$ & $\begin{array}{l}4.2[1-10] \\
17 \text { missing }\end{array}$ \\
\hline
\end{tabular}

*Missing data noted when the amount exceeds 10 percent of the group's sample size.

\section{Physical health}

More than half of all parents interviewed in both rounds describe their health over the past six months as being somewhat or very poor. Most report at least one episode of illness during that period. Among the minority of parents who have living spouses, many of those spouses are also confronting serious health problems. There do not appear to have been large changes over time nor large differences between study groups as far as health status is concerned. It's probable that some of the sickest parents at the first round passed away and were "replaced" in the third round by healthier respondents. 
Table 5 Parents' reported health status in past six months

\begin{tabular}{lcccc}
\hline $\begin{array}{l}\text { Health in last } \\
\mathbf{6} \text { months }\end{array}$ & $\begin{array}{c}\text { Succession } \\
\text { planning } \\
(\mathbf{n}=\mathbf{1 6 3}) \\
\%\end{array}$ & $\begin{array}{c}\text { Comparison } \\
\text { group } \\
(\mathbf{n = 1 0 3 )} \\
\%\end{array}$ & $\begin{array}{c}\text { Succession } \\
\text { planning } \\
(\mathbf{n}=\mathbf{1 6 2}) \\
\%\end{array}$ & $\begin{array}{c}\text { Comparison } \\
\text { group } \\
(\mathbf{n}=\mathbf{1 1 8}) \\
\%\end{array}$ \\
\hline $\begin{array}{l}\text { Somewhat or } \\
\text { very poor health }\end{array}$ & 68 & 57 & 57 & 55 \\
Sick at least once & 87 & 94 & 85 & 91
\end{tabular}

\section{Exposure to the intervention}

Succession planning consists of a number of program components (see Table 1). Overall, 82 percent of parents in the SP arm reported having participated in at least one of the program components. Exposure to specific program activities is listed in Table 6. There is clearly room for improving coverage of the program.

Table 6 Exposure of parents to program components in $2001(n=162)$

\begin{tabular}{ll}
\hline & $\%$ \\
\hline Training: Parent-child communication & 73 \\
Training: Memory book & 65 \\
Training: Agriculture & 61 \\
Training: Will writing & 59 \\
Support to appoint a guardian & 56 \\
Counseled about a will (one-on-one) & 51 \\
Income generating activity start-up funds, materials & 37
\end{tabular}

\section{In their own words: Parents' reports on the impact of succession planning}

Of the 118 parents trained on parent-child communication, 88 percent reported that this had caused them to discuss new things with their children. The most common topics were parent's HIV or health status or future death (72 percent), children's future (41 percent), future guardians (21 percent), and wills and property (15 percent). Another 29 percent stated that as a result of the training, they tried to listen to and understand their children's feelings more. Of the 12 percent of parents who did not report doing anything differently as a result of the training, 10 out of 14 reported that this was because their children were very young. 
Of the 106 parents who had received group and/or one-on-one training about will writing, only a third (32 percent) reported that this had enabled them to write a will. Among those 69 who did not write a will following training, reasons included the following: just finished training and plan to write a will soon (30 percent), afraid or reluctant (22 percent), don't write well (17 percent), don't have property to will (17 percent), and will writing is time-consuming or difficult (10 percent). Of those who did write wills as a result of the SP program, the majority took other important steps, such as appointing an executor ( 82 percent), storing the will in a safe place (72 percent), discussing wills and property with children (68 percent), and discussing wills and property with the standby guardian (41 percent). The most common challenge mentioned by those parents who had written a will was their lack of writing skills.

Many of the parents who were trained in appointing a future guardian reported that they had taken actions as a direct result of the program. Of the 91 parents trained, 71 percent had appointed a guardian, 36 percent had talked to the guardian about the future, 29 percent had informed their children about the guardian, and 26 percent had talked to their children about whom they would like as a guardian. The other parents had not done anything new as a result of the training, already had a guardian, or did not know of anyone who could be a guardian. Others felt they were still too healthy to appoint a guardian or had plans to appoint a guardian soon.

In 2001 two-thirds ( 65 percent, $n=162$ ) of parents in the SP arm reported that they had been trained in how to make a memory book, and 46 percent had begun to or had completed making one. Those who had at least started to make a book were asked what if anything they liked about doing so (see Table 7).

\section{Table 7 Memory books}

\begin{tabular}{lc}
\hline & $\%$ \\
\hline What parents liked most $(\mathbf{n}=\mathbf{5 8})$ & 81 \\
Recording information about me and my family & 40 \\
Helped me to talk about the future with children & 31 \\
Helped me disclose to my children & 12 \\
Allowed me to spend time with my children & \\
What child(ren) liked most (according to parent) $(\mathbf{n}=\mathbf{5 5})$ & 76 \\
Learning about parent, family, their childhood & 15 \\
Time with parent & $13^{*}$ \\
Seeing family photos & \\
&
\end{tabular}

Writing memory books can also be difficult. Eleven parents disliked having to discuss difficult emotional issues. Some mentioned that their children disliked finding out the parent was sick (six) and talking about a parent who had already died (four). 


\section{Hgrizons}

Among parents in the SP arm in 2001, 61 percent reported having received agricultural training. Other assistance received for income-generating projects included financial loans (27 percent), seeds and/or land (14 percent), and tools (10 percent). The majority (76 parents) of those who received any of these forms of assistance reported that it had improved their financial situation. Some were able to use the profits to send their child(ren) back to school (17 parents).

\section{Disclosure of serostatus to children and adults}

Parents' disclosure of HIV status to children. As part of planning for their children's future, many HIV-positive parents find themselves having or wanting to explain their health situation to family members, including spouses, children, and standby guardians. The succession planning program facilitates and supports (although does not require) disclosure by HIV-positive parents. Program support includes group counseling, one-on-one support, and the creation of memory books, which are often tools for explicit or implicit disclosure.

Although most parents and older children were in favor of it, many parents had not yet talked to their children about being HIV-positive at baseline. Between 1999 and 2001, there were significant increases in the proportion of parents who had verbally disclosed to a child in both study groups (see Figure 3). However, by 2001 there was also a significant difference between the study groups where there had been none at baseline, with SP parents disclosing at a higher rate. This suggests that the SP program had a positive effect on parental disclosure to children. This finding remained true after controlling in a multivariate logistic regression model for parent's age, education level, religion, gender, time since HIV diagnosis, time widowed, and district. Furthermore, the effectiveness index for the outcome "disclosure to child" is larger in the SP group (49 percent vs. 31 percent).

Disclosers in the SP group were also more likely to state that, in general, disclosure to children is a "good idea" and were significantly more likely to report that at least one of their children knew about their HIV status through any means ( 88 percent vs. 76 percent, $\mathrm{p}<0.05$ ). These findings are especially important in light of baseline findings that older children wanted parents to "tell them the truth" (see Gilborn et al. 2001). 


\section{Figure 3 Percentage of HIV-positive parents who verbally disclosed HIV status to a child}

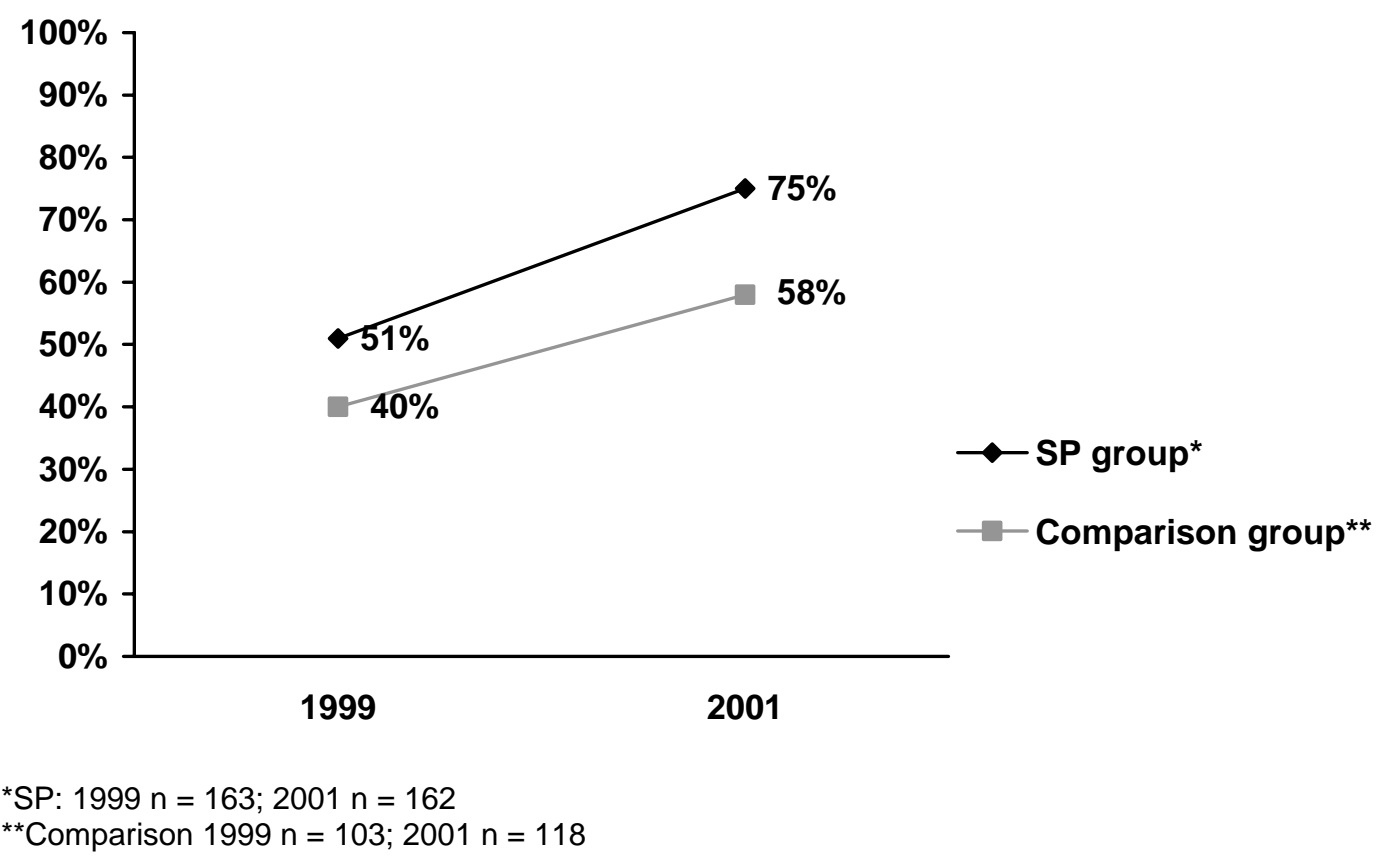

In-depth interviews with 11 counseling aides in the SP areas conducted after the second observation confirmed that counselor aides (CAs) were indeed encouraging parents to disclose to their children. CAs were in favor of disclosure because it would allow children to learn to protect themselves from AIDS and to prepare for their parents' eventual death. "It should not be a shock to the children when the parent dies," explained one CA.

When parents do not disclose, many children discover the truth through more difficult means, like teasing, gossip, or witnessing their parent going to an AIDS clinic. There was a general consensus among CAs and parents alike that disclosure is useful with children over 12 years old, but inappropriate for younger children.

It was difficult at first. But after good training on being open, parents are doing it without any further difficulty. They are all disclosing. It has had a good impact in terms of creating awareness in children about HIV/AIDS and how to protect themselves. Parents feel "free" after helping children to know what is going on and how to help themselves. I feel it is very good because if a parent is open to a child, s/he'll have saved that child from so many problems, like fearing being told by others. Many children know at some level. But with the knowledge from their parents, they will be less worried about abuse from friends. Also the children now know how HIV/AIDS is spread. They'll try to protect themselves...

Counseling aide, Tororo 


\section{Hgrizons}

Parents first feared how children would react, whether they would be judgmental. This was a very big challenge. But in the end they realized they had no choice: many are in the late stages. Children often already know through gossip....The impact is that parents feel relieved and in a better position to discuss the future. Many children, especially the older [children], are afraid of the future. They really fear that they will be chased from their land, worry about who will look after them, fear for the younger siblings. But I do think disclosure is a key to solving problems.

Counseling aide, Tororo

Sixteen in-depth interviews were conducted with HIV-positive parents enrolled in the SP program after the final observation, on the topic of disclosure to children and others. Most (13 of 16) parents had disclosed their HIV status to at least one child since the SP program began. In general, parents chose to disclose to children considered trustworthy (i.e., who would keep parent's HIV status a secret), were mature, and were 12 years or older. Likely heirs were also candidates for disclosure. Fathers tended to disclose only to heirs, while mothers tended to disclose to multiple children and expressed greater concern for the emotional impact on children. Parents were motivated to disclose to children meeting these criteria due to the need for the children's help during illness and beyond, to prepare children, and to inform them about familial property. Others said that after disclosing, they urged their children to behave well so that they would attract the sympathy and assistance of kin when the parent passed away.

In some cases disclosure is achieved passively by, for example, leaving a memory book in full view of children. Parents sometimes "disclose" to their children very indirectly in the form of rebukes or threats about "what will happen" to the children when the parent dies. One HIV-positive woman gave an example of a remark a mother might make to hint at the situation without addressing it explicitly: "You kids are so stubborn, careless, and naughty, but one day you will suffer when I die."

Positive consequences of disclosure for the children, as reported by parents, included strengthening family bonds. All parents (16 of 16) stated that disclosure can strengthen family bonds and encourage children to take precautions against HIV/AIDS.

Some negative consequences were also reported, such as children getting seriously upset by the news of their parent's illness. In some cases, children had run away from home (three of 16) or reacted violently to the parent's disclosure (one of 16). Further research is needed to determine why some children react in these ways, when it is appropriate to disclose, and-most importanthow children can be supported in coming to terms with parents' HIV status, illness, and death.

Clearly, learning that a parent is HIV-positive is never easy for a child and can provoke not only sadness and anger but also overwhelming fear about survival. Interviewees asserted that disclosure must be accompanied by some reassurance that the child will be provided for. Specifically, they felt that the program must guarantee children's access to material needs and ongoing counseling as a prerequisite to promoting parent-to-child disclosure, to offset the fear and uncertainty about survival that arises with disclosure. In this light, parents reinforced the need for greater access to income-generating opportunities for HIV-positive parents in the program. Some female 
respondents felt children under 18 should be tested for HIV and provided with treatment and services if positive. Interviewees also expressed a need for community sensitization about HIV and the importance of disclosure.

Parents' disclosure of HIV status to adults. Disclosure to other adults was also explored during qualitative research. In general, parents reported that they disclose their serostatus selectively to adults who are trusted and likely to be helpful. Parents disclose to selected adults in order to gain support during times of illness and gain access to services, including SP. By and large, parents reported that disclosure to these carefully selected individuals led to material and emotional support. Persisting stigma, violence, and other repercussions are still a deterrent to greater openness about HIV status in the general community.

Specific positive outcomes of disclosure to fellow adults included receiving moral, material, and spiritual support. Some respondents were supportively encouraged to confirm their status with an HIV test. And in some cases the person disclosed to, especially spouses, would also get tested: "My disclosure to some of my siblings encouraged them to take the HIV test. Two of them were found to be HIV-positive. So, since then, the family has become more united, as I am no longer treated as a sexually irresponsible person" (HIV-positive mother in Luwero). For some, disclosure allowed access to services related to their health situation. Disclosing the true cause of illness also helped to dispel accusations of voodoo and witchcraft and prevent acts of revenge that sometimes occur when someone is thought to have been bewitched.

Negative consequences of disclosure to adults included experiences of stigma, verbal abuse, spousal abuse, blame, and family break-ups, with greater familial consequences for and blame directed at women. Men reported "not being taken seriously" by other males to whom they disclosed (often during social activities involving alcohol) or being accused of pretending to be HIV-positive in order to gain access to services.

In general, parents disclosed to fellow adults through explicit verbal communication. Twelve out of 16 parents interviewed in-depth had disclosed to their spouse. In dealing with spouses, women sometimes coaxed them into getting tested together so that the "results would do the talking" and the woman would be less likely to be accused of "bringing AIDS home." They had to be sure not to tell their husband when he might be irritable and get angry. Two women reported that their husbands disclosed to them after returning from a bar. As with children, sometimes disclosure to adults is done passively, for example, by leaving a memory book in full view.

\section{Appointing guardians}

Although most parents (86 percent) in the two study groups combined felt it was important to appoint a guardian, only about half (53 percent) of parents had done so at the time of baseline data collection. Some of the parents who had not appointed a guardian felt that there was someone who would care for their children anyway. Obstacles to appointing guardians reported by parents at baseline included not knowing anyone able or willing, not yet having thought about it, still being in 


\section{Hgrizons}

good health, and not wanting to reveal their HIV status to potential guardians. Others stated that the person they had in mind to be the guardian was old or in poor health.

After two years there were dramatic increases in the proportion of parents who had appointed a guardian in both the SP and comparison groups. Among parents in the SP arm, this proportion rose from 56 percent to 81 percent ( $\mathrm{p}<0.05$ ). The increase was from 47 percent to 63 percent in the comparison arm $(\mathrm{p}<0.05)$. While there was not a significant difference between study groups at baseline, there was a significant difference at Round 3, with SP parents being more likely to have appointed a guardian (81 percent in SP vs. 63 percent in comparison; see Figure 4). This finding was found to be true after controlling for age, education, religion, sex, time since HIV diagnosis, time widowed, and district in a multivariate logistic regression model. Moreover, the effectiveness index is much larger in the SP group (57 percent vs. 30 percent). This suggests that despite a similar trend in both groups, the SP program may indeed have contributed to an increasing proportion of parents appointing guardians. In addition, among parents who had appointed guardians, those in SP reported greater confidence in the appointed guardian than did comparison group parents.

Figure 4 Percentage of HIV-positive parents who appointed guardians

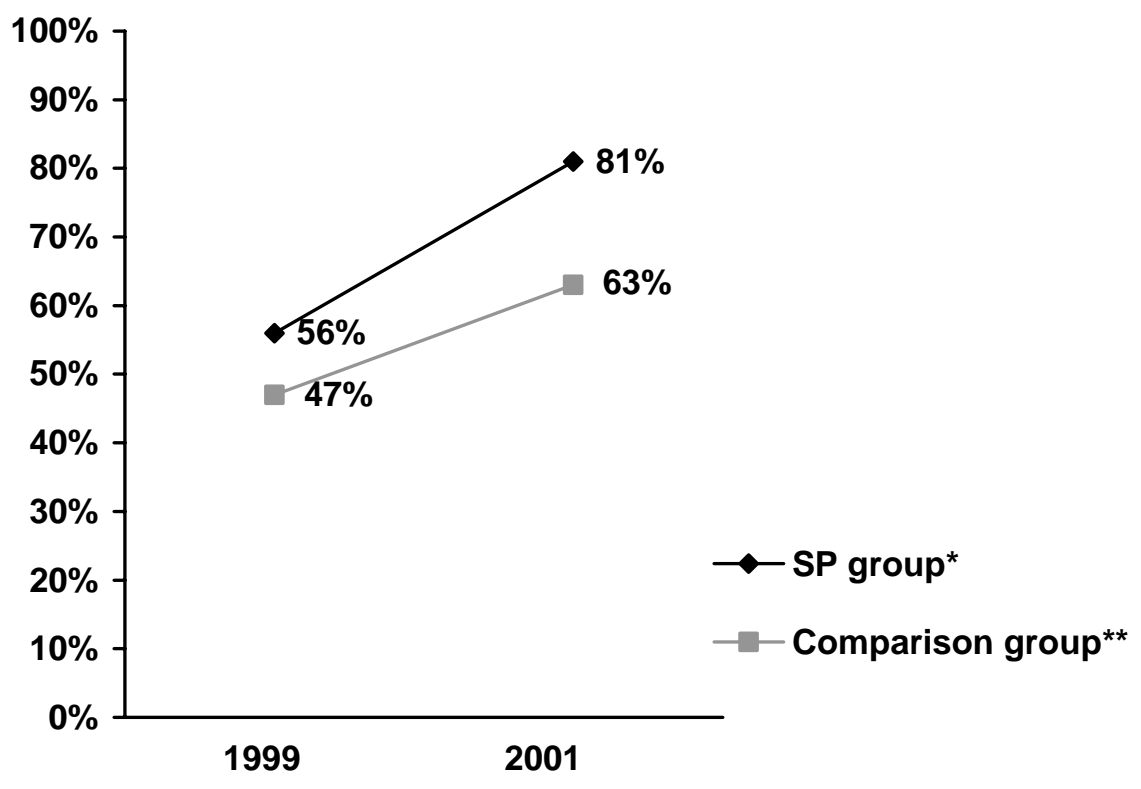

${ }^{*}$ SP: $1999 \mathrm{n}=163 ; 2001 \mathrm{n}=162$

${ }^{\star *}$ OS: $1999 \mathrm{n}=103 ; 2001 \mathrm{n}=118$

After two years, parents in the succession planning areas were significantly more likely to report that they had a guardian and that one or more of their children knew about the guardian (44 percent in 1999 vs. 65 percent in 2001, $\mathrm{p}<0.05$ ). This suggests that SP parents were making more explicit 
plans for the future, communicating more with children, and attempting to reassure those children about the future.

There were no changes, however, in parents' likelihood of reporting that their children had been involved in the selection of a guardian or that they had discussed living arrangements with the guardians. Qualitative research and data interpretation meetings alike revealed that it was not felt to be appropriate to involve young children in this decision, though some parents sought the input of older children.

According to counseling aides, parents have responded very positively to being encouraged to appoint guardians. CAs advise parents to select a guardian who is responsible with money and property, local, trustworthy, hardworking, earning a steady income, caring, close to the family and children, and helpful with the family's problems.

"It is a really good idea to leave somebody [i.e., designate a guardian] because once you fail to do it, relatives can abandon the children and they end up on the streets, because nobody cares or was given the formal responsibility."

Counseling aide in Luwero

Overall, CAs feel it is more important to identify a person with the above qualities than to restrict the choice to relatives. "Sometimes they choose a good neighbor instead of a relative." CAs also encourage parents to find a guardian in the same community so that children will be familiar with the person and not be uprooted-but this still seems to be difficult for parents, many of whom are inclined to appoint relatives who are far away. CAs felt that appointing a guardian ahead of time helps the guardians and children alike. Standby guardians can prepare, and children will know where to go for help when needed (see section on standby guardians, page 28).

\section{Wills and property grabbing}

A striking finding at the baseline stage of this study was that fears and concerns about property grabbing were quite common. Property grabbing is when inherited property is taken from the surviving family members and heirs to whom it rightfully belongs. Almost one-third (31 percent, $\mathrm{n}=147$ ) of widowed females in the two study groups had themselves experienced property grabbing at baseline. At the same time only 24 percent combined had made any arrangements for their property (i.e. through a will or other verbal means), and less than one in 10 had written a will. This seemed to suggest a need for some form of legal assistance and other activities that might reduce property grabbing and alleviate fears.

Succession planning was designed to include group training for and one-on-one assistance with writing wills. Unfortunately, this aspect of the intervention was slow to start and proceeded at low intensity. In one of the two districts, Luwero, this activity took off after a full year's delay. In addition, according to program implementers, news about the will-writing activities in the SP areas spilled into the other study group areas. Thus some unanticipated parallel activities may have occurred in the comparison group. 


\section{Hgrizons}

There were no significant differences between the study groups at the final observation in terms of the proportion who had written wills, appointed executors, and made other related arrangements, nor in knowledge of women's and children's property rights, which makes it difficult to conclude that the will-writing component of the program made a difference.

However, there was a trend toward more will writing and greater legal knowledge in both groups (Table 8). For example, a key outcome of interest was the proportion of parents with a written will. After two years, this proportion roughly doubled in both the SP and comparison groups; this change was significant for both groups. Since will writing is so untraditional and uncommon in the general population, it is unlikely that the change was due to a secular trend; a spillover effect seems more likely.

Table 8 Wills and property

\begin{tabular}{lcccc}
\hline & $\begin{array}{c}\text { Succession planning group } \\
\text { Baseline } \\
\%\end{array}$ & $\begin{array}{c}\text { Follow-up } \\
\%\end{array}$ & $\begin{array}{c}\text { Comparison group } \\
\text { Baseline } \\
\%\end{array}$ & $\begin{array}{c}\text { Follow-up } \\
\%\end{array}$ \\
\hline Have a written will* & 9 & 20 & 10 & 21 \\
$\begin{array}{l}\text { Appointed executor } \\
\begin{array}{l}\text { Think property will be } \\
\text { distributed as you want }\end{array}\end{array}$ & 46 & 48 & 35 & 37 \\
$\begin{array}{l}\text { Know women's property } \\
\text { rights in absence of a will* }\end{array}$ & 63 & 89 & 70 & 78 \\
$\begin{array}{l}\text { Know children's property } \\
\text { rights in absence of a will* }\end{array}$ & 75 & 81 & 60 & 86 \\
* Statistically significant pre- vs. post-intervention differences in both study groups. $(p<0.05)$
\end{tabular}

Further analysis was done, while disaggregating the sample in various ways (those with wills, by sex, and those reporting actual participation in legal training). For example, among only those parents with wills in 2001, those in SP were more likely than comparison parents to take additional related steps such as informing a child about the will, telling family members where the will was stored, and appointing an executor.

When the results are disaggregated by sex, it appears that although the legal intervention might have been weak, it may have had significant effects on the actions of male respondents. Thus, among males in SP, there were significant pre- vs. post-intervention increases in the proportion that had written wills (from 16 percent in 1999 to 37 percent in 2001, p < 0.05) and in the proportion of men who had appointed an executor (from 57 percent in 1999 to 83 percent in 2001, p < 0.05). There were no significant changes in these outcomes among men in the comparison group. These 
results should not be viewed as conclusive, since the sample sizes of men were very small $(n=46$ in $1999, \mathrm{n}=29$ in 2001). However, they do suggest that the intervention may have been making a greater difference with male beneficiaries. One could argue that this change among men is critical, given that men are often the first parent to die and have far greater access to physical property than do women, and therefore have more property to distribute.

Data were also analyzed by splitting the SP respondents by whether or not they reported that they had actually attended legal training. Analyzed in this way, the data reveal that respondents who actually reported exposure to the legal intervention were more likely than those in SP arm who reported not having participated in legal training to have written wills ( 25 percent vs. 12 percent, $\mathrm{p}<0.05$ ), to have an executor (54 percent vs. 38 percent, $\mathrm{p}<0.05$ ), and to have discussed property laws with their children ( 42 percent vs. 32 percent, not statistically significant).

Qualitative data collected from both program implementers and parents enrolled in the SP program highlight the formidable cultural obstacles faced by the program in trying to introduce will writing. Indeed, this component of the SP program is probably the most challenging to implement successfully. First and foremost, will writing is not traditional in Uganda and is in fact considered "bad luck." Like any other step to "prepare for death," the preparation of a will is believed in fact to hasten death. Thus people are very fearful about writing wills. Other cultural challenges include the tradition of extreme secrecy about one's belongings. As a result, program participants were reluctant to record their possessions "in writing" or to accept the assistance of counseling aides in preparing the will. Traditionally, male heads of households make their properties known to the clan leader, who is solely responsible for distributing property at the time of the man's death. Furthermore, the majority of a man's property traditionally goes to his eldest son, or if the son is too young, to the man's brother for safekeeping until the son is old enough to care for it. These and other barriers are summarized in the sidebar below. 


\section{Hgrizons}

\section{Barriers to will-writing in Uganda}

- Traditionally wills are verbal, not written.

- Traditionally property is identified and distributed only posthumously, by clan leaders.

- Widespread belief that wills and "preparing for death" will cause death.

- Wills and revealing one's property before death sometimes lead to property grabbing and conflict, thus there is extreme secrecy about belongings.

- Women and young children do not traditionally own or inherit property.

- Poor knowledge and enforcement of laws protecting women and children's property rights.

- Low literacy limits capacity to write wills.

- Widespread reluctance to write a will until one is very ill or bedridden.

- Limited capacity in rural areas among NGOs in legal issues.

- Relative difficulty of engaging males in will training.

- Fears that wills could be plagiarized and falsified.

- Wills are associated with European colonialists and thus resisted.

- Some people have limited or no household property to will.

- Lack of appropriate, secure places in which to store wills.

Writing a will is one of the most difficult things a person can do in this culture. It is seen as bad luck, a final sacrament. Therefore the rise in will writing will take place only gradually. People are now realizing the importance of wills. SP will only be successful with wills. ...Now people are demanding wills! If the research continues, the graph will continue to rise way up.

Counseling aide at data interpretation meeting, Luwero

Wills are confidential. People do not like to discuss it with others. So it is difficult for the counseling aides to get involved.

Counseling aide at data interpretation meeting, Luwero

Despite these barriers, qualitative research did reveal a considerable degree of interest and confidence in the effectiveness of wills, with a number of SP parents reporting having written wills as a direct result of being in the program (26 of 69 women and 17 of 32 men in the focus group discussions), and with a primary interest in protecting their children's access to property. Overall, counseling aides stressed that the decision to make a will was long and difficult and that change would occur slowly but surely.

After the program started, there were a number of instances in which a will was effective in protecting survivors' property rights. Witnessing these cases motivated more parents to write wills. Spillover of ideas about will writing into the comparison community also suggests a certain level of demand and acceptability of the program: "Nearby sub-counties hear about will-writing in the SP sub-counties and want to make wills as well," explained a counseling aide at a data interpretation meeting in Luwero. Those who were in favor of will writing explained that written wills reduce 
conflicts over property, serve as hard evidence to settle disputes, and deter survivors and caretakers from liquidating property.

Individuals in the focus group discussions reported that men's participation is critical. They also reported that women expressed the greatest interest in will writing. Women may be more interested because they are at greater risk of losing property and would have more to gain from any program that protected their access to property. However, in the survey data, men were just as likely as women to report that they had attended training. Program managers report that male participation in will-writing has continued to improve since the study concluded (see Update from the Field, page 39).

Unfortunately, there were other reports of written wills being overridden or causing family disputes, some of them violent. Some women reported that they used a spouse's will to maintain control of their property, while others had wills but found them ineffective. In addition, wills seem to be more effective when the survivors are adults or older children, and far less effective when the survivors are young children.

\section{Contrasting experiences of women regarding effectiveness of wills}

"When my husband passed away, the will did the talking. All my children have continued to go to school. Though life now is hard and we lack some essentials, what was willed to us we got."

Mother and SP participant in Luwero District

"These wills are not respected at all. My late husband left a will in which I was given two houses, a plot in Malaba town, and lots of land. But my father-in-law has made it impossible for me to access these things. Most of them have been sold, and the proceeds don't benefit us. I have tried to engage the Local Councils, police, probation, and courts of law, but my father-in-law has his way. I have given up trying to get what belongs to me. This is because I will end up using the little money that I have to fight a war I cannot win."

Mother and SP participant in Tororo District

Clearly, much remains to be done in order for this program to be successful in protecting survivors' access to property. The local appropriateness of wills is debatable. Other solutions, or variations on this one, may be more effective. There is a serious need for the "social legitimization" of whatever solutions are tried. The sidebar that follows displays a list of recommendations that emerged from respondents in the qualitative work and from data dissemination meetings on how to improve this aspect of succession planning. 


\section{Hgrizons}

\section{Recommendations for will-writing program}

- Increase involvement of local government and religious officials, clan leaders, and elders in defending wills.

- Expand program to all adults, not just those in SP, so that will writing does not become further associated with illness and death, and because will-writing is a responsible thing to do and relevant to all adults.

- Educate the entire community about legal issues, women and children's rights, and wills.

- Promote the secure storage of wills with churches and mosques.

- Increase male participation.

- Allow for a long process of adjusting to the idea of writing a will at the individual and community level.

- Tape record the contents of wills (there was a feeling that while written wills could be falsified, audiotapes could not).

\section{Comments from program participants}

"In our village, the LCs (local councils) and clergy command so much respect, so-if they endorse a program and are involved in mobilization, it's likely that many people will come for will-writing training and also write wills."

HIV-positive parent in SP, Tororo

"It would help if we did not restrict the program to PLHA. We should reach all adults with the message about the importance of wills."

Counseling aide at data interpretation meeting in Luwero

"It is essential that the CA has earned the trust of the client... The CA must be patient and let some time go by and focus on other things before approaching the issue of wills."

Counseling aide at data interpretation meeting in Luwero

"Clients need a lot of ongoing support from CAs in order to complete the wills." Counseling aide at data interpretation meeting in Luwero

\section{Program I mpact on Standby Guardians}

When interpreting study results about standby guardians, it is important to note that not all parents identified a standby guardian for interviews. In addition, researchers were only able to reach about a third of those who were identified for interviews. This was mainly because many standby guardians lived outside the study area. 
Because of the small sample size, few statistically significant differences were found over time or between study groups, making it difficult to draw conclusions about the effect of SP on standby guardians. Even where differences were found, one must keep in mind that those standby guardians who were reachable for interviews were more likely than distant standby guardians to have benefited from the program, thereby biasing the results. Because of the lack of statistically significant differences over time and between study groups, this section reports primarily on standby guardians in the SP areas only, noting statistically significant changes over time only where they exist.

\section{Profile of the standby guardians}

At baseline, 81 percent (214 of 266) of parents in the two study groups combined identified someone who might care for their children in the future. This figure combines both parents who reported they had actually arranged for a guardian and those who had not but could name someone likely to care for their children if needed. The research team attempted to interview all those named; however, only 84 (39 percent) could be reached for interviews. At Round 3, 85 percent ( 239 of 280) of parents named such a person, but only 74 (31 percent) of them could be reached.

The table below outlines a few characteristics of standby guardians. The majority of standby guardians actually reached for interview were male and in their late 30s. Except for standby guardians in the comparison group at baseline, most were married. Many are already caring for one or more orphans, raising concerns about their ability to take on additional dependents when the HIV-positive parents die.

\section{Table 9 Characteristics of standby guardians}

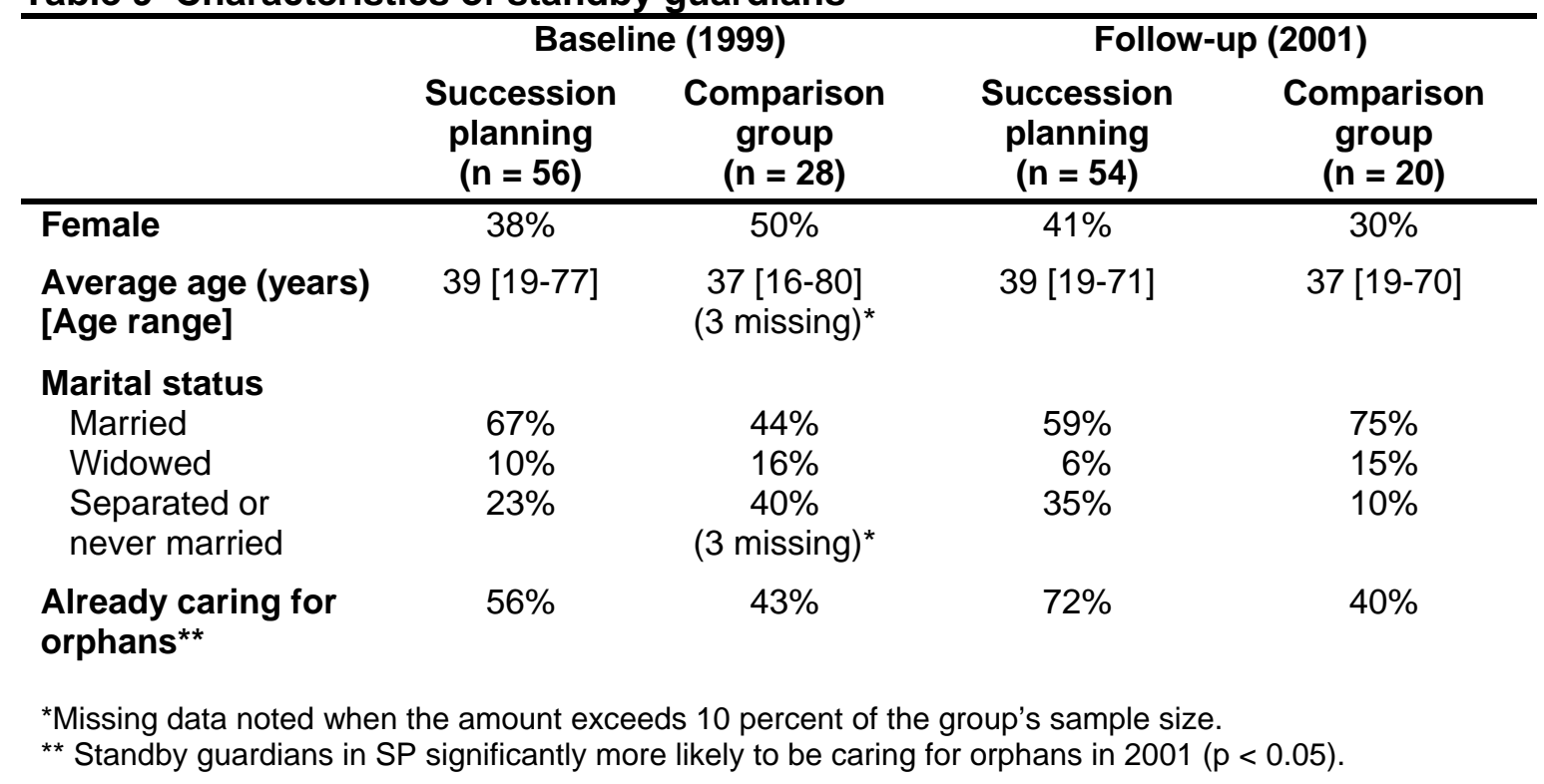




\section{Hgrizons}

\section{Exposure to the intervention: Does SP reach the future guardians?}

It appears that the SP intervention did not reach appointed standby guardians very well. As stated above, the researchers were able to reach only a minority of individuals identified by parents as standby guardians. Because many of the standby guardians live outside the program area, most did not participate in SP. Even among those standby guardians in the SP area who could be reached for interviews in 2001, only 28 percent (15 of 54) reported having participated in any training about guardianship.

During data interpretation meetings, researchers explored reasons why many parents appoint guardians outside the community. Participants explained that this may be because there are fewer existing conflicts with distant relatives and because those relatives in the best position to care for the children may not be closest geographically. Since the time of this research, Plan program managers report that parents are increasingly turning to unrelated standby guardians in their communities. In some cases, CAs themselves are stepping in as standby guardians due to the shortage of relatives in the community capable of caring for orphans (see Updates from the Field, page 39).

Finally, standby guardians reached for interviews differed in a number of respects from the current guardians interviewed. (Current guardians are not reported on in this report but were included in the larger study). Most notably, standby guardians were predominantly male and younger, while actual (i.e., current) guardians were predominantly older and female. This suggests that they may be discrepancies between the person appointed by the parent and the person who actually "comes through" for the children once the parents die. At data interpretation meetings, community participants reported that men appointed as guardians often do not fulfill their responsibilities once the parent dies, especially if there is not property to be gained by the guardian. Thus, women tend to fill in and take ultimate responsibility for the children.

\section{Standby guardians report on impact of succession planning}

As stated above, only 28 percent of standby guardians reached for interviews reported having received training about guardianship (15 of 54). Fortunately, those who received training reported benefiting in the following ways: learning how to be a responsible guardian, learning to be sensitive to the needs of orphans (for example, to love them as their own children), and preparing for the future, financially, emotionally, and otherwise. Only four individuals reported receiving any services aside from training.

Preparedness and willingness to care for children in the future. Almost all (52 of 54) individuals identified by parents as standby guardians and interviewed in the SP arm at Round 3 had made a firm decision to foster the children. Most (72 percent, $n=54)$ had discussed this possibility with the parents. However, only a third $(n=54)$ of standby guardians interviewed in the SP group stated that they had made any preparations for their possible future responsibilities as guardians. 
Only about a third ( 32 percent, $n=54$ ) of the appointed standby guardians in SP reported that they felt completely prepared for their responsibilities, up from 21 percent at baseline $(n=56$, not statistically significant). However, 43 percent $(n=54)$ reported that they felt somewhat or completely unprepared. Ironically, this was higher than in the comparison group, in which only 20 percent ( $\mathrm{n}=20$, not statistically significant) stated they felt somewhat or completely unprepared.

Standby guardians' worries were mostly financial, including concerns about how to pay for the child's schooling, food, clothes, and so forth. Some worried about being overwhelmed by responsibilities, about their own health problems and physical capacity to care for the children, and about the child possibly becoming ill with HIV. Forty-one percent of standby guardians in SP stated that the parents' health conditions raised special concerns about caring for the children. These worries were similar to those expressed by standby guardians at Round 1 and those expressed in the comparison group.

\section{Present level of involvement with child and family}

Children are generally more comfortable with guardians they already know well. For this reason, we explored standby guardians' current relationship with the children's family. Their roles in assisting families while parents are ill may also be an indication of their commitment to future child-rearing responsibilities.

Most standby guardians interviewed are already actively involved in supporting the HIV-positive parent's family. For example, in the SP arm at Round 3, 81 percent $(n=54)$ reported material assistance, and 70 percent reported other forms of practical assistance. (These figures are similar to Round 1 and comparison group figures.) Almost all (96 percent) see the children a few times a week or more often. The overwhelming majority reported that they know the children very well (94 percent) and that the children would feel comfortable discussing a concern with them (93 percent). Most (78 percent) reported that the child knew the standby guardian would care for them, with the others saying either that the child did not know or that they did not know whether the child knew.

(It should be noted, again, that researchers were unable to reach standby guardians who live outside the program area.)

\section{Capacity to care for children in the future}

Capacity to care for orphans is measured through guardians' self-assessment of their ability to provide for orphans, as well as household and socioeconomic characteristics.

Standby guardians in the two study groups at Time 3 are similar with respect to socioeconomic status and health. Nearly all have access to land, grow crops, and raise livestock. Those in SP tended to be of just slightly higher socioeconomic status, which would indicate greater capacity to support orphans in the future, but there were no significant differences. 


\section{Hgrizons}

Just over a third (39 percent) were confident they could send the child(ren) to school, 69 percent were confident they could feed the child(ren) enough, and 87 percent were confident they would have time to tend to the child(ren)'s problems. In each case, standby guardians in SP at Round 3 were more confident than they had been in Round 1 and more confident than the standby guardians in OS, but none of the differences were significant.

Guardians' capacity to care is undoubtedly affected by the number of able-bodied adults in the household relative to the number of dependent children. The majority (59 percent in the SP group and 75 percent in the comparison group) of standby guardians are married, as opposed to being widowed, separated or never married (see Table 9). What is worrisome, however, is the large proportion (72 percent in SP vs. 40 percent in comparison, $p<0.05$ ) of standby guardians who have already taken on care for other orphans, especially in the SP group. The fact that standby guardians in SP at Round 3 are less likely to be married and more likely to have other orphans in their care relative to standby guardians in the comparison group or in the SP group in 1999 raises questions about capacity to care even in SP areas.

Some standby guardians have health problems of their own that may impede their ability to care for additional dependents. For example, 22 percent of standby guardians in SP and 15 percent of standby guardians in the comparison group in 2001 reported that their health had been somewhat or very poor in the preceding six months. One standby guardian in each group reported being HIVpositive.

\section{Standby guardians as protectors of children's property}

Among both groups of standby guardians at baseline, awareness of the right of a wife and children to inherit property if explicitly stated in a will was high (89 percent or above in all cases). Far fewer respondents were aware that women and children are legally entitled to property when the husband/father dies even in the absence of a will (Table 10). This is one area in which the SP program seems to have made an impact by Round 3. For example, over time in the SP areas there were significant increases in awareness that both women and children's rights to a portion of the inheritance (from spouse and father respectively) are protected by law even without a will. Also, by Round 3 standby guardians in SP were significantly more likely to know that women's property rights were legally protected in the absence of a will than were standby guardians in the comparison group. Differences had not been significant at Round 1. 
Table 10 Standby guardians' awareness of women and children's legal property rights

\begin{tabular}{|c|c|c|c|c|}
\hline & \multicolumn{2}{|c|}{ Baseline (1999) } & \multicolumn{2}{|c|}{ Follow-up (2001) } \\
\hline & $\begin{array}{c}\text { SP group } \\
(n=56) \\
\%\end{array}$ & $\begin{array}{c}\text { Comparison } \\
\text { group } \\
(n=28) \\
\%\end{array}$ & $\begin{array}{c}\text { SP group } \\
(n=54) \\
\%\end{array}$ & $\begin{array}{c}\text { Comparison } \\
\text { group } \\
(\mathrm{n}=20) \\
\%\end{array}$ \\
\hline $\begin{array}{l}\text { By law, women have } \\
\text { a right to deceased husband's } \\
\text { property if there is no will }\end{array}$ & 69 & 56 & 94 & 70 \\
\hline $\begin{array}{l}\text { By law, children have } \\
\text { a right to deceased father's } \\
\text { property if there is no will**}\end{array}$ & 78 & 71 & 94 & 85 \\
\hline
\end{tabular}

\section{What About the Children?}

The ultimate goal of SP is to ensure a better future for children whose parents are HIV-positive. A two-year study is not sufficient to assess the long-term effects of SP on children once they are actually orphaned. For this reason, the current impact analysis focuses on steps taken by parents and standby guardians exposed to SP to increase the likelihood that AIDS-affected children are better prepared to face the future.

The following dimensions of child well-being were examined for the two age groups (children 5 to 12 years old and 13 to 19 years old): physical health, nutrition, education, material well-being, exposure to negative events such as stigma and abuse, and emotional well-being. Overall there were no pronounced differences over time in these areas during the period of the study. This is because SP seeks to improve the future well-being of children and most program components actually target adults: parents and standby guardians (see Figure 2). Nonetheless, this raises questions about whether the program should also strive to improve the present (not just the future) well-being of children whose parents are HIV-positive.

During data interpretation meetings, counseling aides and other community members were asked why health and nutrition status might remain the same or even worsen in the presence of SP. First and foremost, a serious drought in Tororo District likely had a negative impact on food security and health. However, many of them also remarked that the "downward pressure" of the ever-worsening AIDS epidemic outpaced any benefits of the program to children. At the same time SP was taking off, individual households continued to experience additional deaths and to take in orphans.

Dependency ratios continued to worsen throughout the community. Thus any program would have had to address ongoing declines in community welfare. 


\section{Hgrizons}

\section{More parent-to-child communication reported by older children in SP}

Older children (13 to 19 years old) who were aware of their parents' HIV-status were asked whether they felt it was a good idea for parents to disclose to their children. At baseline, the majority of older children were in favor of this open communication for the following reasons: so they could know the truth, avoid HIV/AIDS, know what to do when the parent dies, prepare for the parent's death, and discuss guardians and wills. In effect, these youth were telling the researchers that better parent-to-child communication about parental HIV status would improve their wellbeing.

Perhaps one of the most important effects of SP occurred among older children, who predominantly expressed a desire for parents to be open with them about the parents' HIV status. Between 1999 and 2001, there was a significant increase (35 percent vs. 57 percent, $\mathrm{p}<0.05, \mathrm{n}=$ 89 at Round 1 and $n=88$ at Round 3) in the proportion of older children in the SP group who viewed parent-to-child disclosure positively and who reported that a parent disclosed his/her status.

Qualitative research revealed a general consensus among parents and counseling aides that disclosure may not be appropriate for children 12 and under. They also stated that the impact of disclosure on younger children depends a lot on their intellectual maturity (those under eight may not understand, those between eight and 12 might be quite disturbed), the number and health status of parents living, and what they've learned about HIV/AIDS in school. 


\section{Discussion of Results}

Findings from this study suggest that succession planning is a promising approach for increasing the extent to which HIV-positive parents take action to ensure a better future for their children. Despite AIDS-related stigma and cultural resistance to acknowledging illness and death, qualitative research indicates that the approach met with a high degree of acceptability among HIV-positive parents and counseling aides who carried out the program. SP principles likely "spilled over" into neighboring communities, also suggesting widespread acceptability of SP services.

The program was particularly successful in promoting disclosure and open discussion between parents and children and in encouraging parents to appoint guardians. Will writing proved a more challenging program component, due primarily to taboos against "preparing for death."

Standby guardians and children were less well reached and served by the program. The main barrier among standby guardians was the fact that many lived outside the program area and program components for them were relatively weak. Furthermore, males tend to be appointed as standby guardians, whereas it is females who ultimately tend to take responsibility for children when the parents die.

The ultimate goal of succession planning where children are concerned is to improve their future well-being. More research is needed to determine whether the program succeeds in this. In the shorter term, however, succession planning does appear to improve communication between parents and older children, which is likely to benefit the children.

The succession planning program was implemented in two different districts. Different local NGOs implemented the activities in each district, which naturally led to some variability in the intensity and nature of activities. Like all pilot programs, this one met with some delays and growing pains along the way. Overall, the SP program was less intensive than anticipated. For example, only 82 percent of eligible parents in the SP areas reported having participated in any component of the program by the final observation in 2001 .

There is also some evidence that the ideas and activities related to SP spread to the comparison areas. Some respondents in the comparison areas reported that they had participated in SP activities. This may be either a misunderstanding of the other things they had been involved with or an indication that there were some impromptu efforts in the community or by local organizations to replicate appealing aspects of the intervention.

A look at outcomes also suggests some contamination into the comparison areas. After preliminary data analysis, the research team was puzzled to find that improvements in some outcome variables directly related to the SP program were also found among the comparison group (although often to a lesser degree). This unexpected finding was discussed with counseling aides at data interpretation meetings. Program implementers explained that news of the SP program had spread across the boundaries of the study areas and that neighboring communities were demanding the same 


\section{Hgrizons}

services. Because some of the same organizations and counseling aides work in both study areas, it is possible that they responded to this demand in an ad hoc fashion.

This "spillover effect" limits the study's capacity to deduce statistical inference about the program's effects. However, it may also be a testimony to the SP program's appeal and acceptability. The overall trend was a desirable change in the outcomes of interest over time seen in both the SP and comparison areas, with a generally larger and more significant change in the SP areas.

Some aspects of the program, however, require strengthening or adaptation; see the Program and Policy Recommendations (page 37) as well as an Update from the Field (page 39). 


\title{
Program and Policy Recommendations
}

\section{Program and Policy I mplications}

\author{
Successful implementation of a comprehensive, integrated succession planning \\ program requires an implementing organization(s) with a wide range of technical \\ capacities.
}

As a team, staff and volunteers must have literacy and skills in legal matters, food security and livelihood matters, income generation, and child, adult, and family counseling. Organizations with a narrower focus may want to consider a subset of activities, for example, memory books alone. Nonetheless, there are advantages to a comprehensive, integrated package.

Certain aspects of the program must be strengthened to minimize trauma to children when they learn about their parents' HIV status.

The SP program's emphasis on parent-to-child disclosure was well accepted. Parents, youth, and counseling aides are predominantly in favor of disclosure to children over age 12. However, learning that a parent is HIV-positive is invariably upsetting. Among other things, children wonder how they will survive. Material and other support must be in place prior to disclosure so that children can be reassured about their future survival. Parents need more training and support to communicate to children sensitively and to identify children who may not be ready for the news. Additional direct counseling and support to children are needed on an ongoing basis as they process the information.

\section{Enhance involvement of leaders, men, and the general community.}

More sensitization is required at the community level about the importance of disclosure, planning for the future, and supporting children in AIDS-affected households. The community and local leaders must be engaged in upholding wills and property rights in particular. Men are underinvolved both as parents and standby guardians. In general, there is a need to increase interest, participation, and commitment in the program by men, who for cultural and other reasons have shown less interest in the program, either as parents or standby guardians.

\section{More opportunities should be created for the participation of standby guardians in the entire SP program.}

Parents in succession planning responded well to being encouraged to identify standby guardians for their children. There is consensus that children should be placed with familiar guardians in their 


\section{Hgrizons}

own communities. The program was clearly associated with an increase in the proportion of parents who did so, though few parents went so far as to involve their children in these decisions. Yet there are some formidable challenges to the program's premise that guardians can and should be appointed ahead of time and can be counted on to fulfill this obligation in the future. Some families do not have any relatives or friends capable of assuming this responsibility. Others only have appropriate guardians in distant communities. There is also the issue of appointed standby guardians, especially males, shirking their responsibilities when the time comes. Programmatic solutions to some of these problems might include:

- Intensifying program activities for standby guardians, with emphasis on income-generating opportunities and collaborative projects with the AIDS-affected families.

- Devising ways to involve distant standby guardians in program activities during visits to their home villages.

- Encouraging the appointment of unrelated standby guardians in the local community.

- Ensuring that female members of the standby guardian's household are targeted, because females tend to be more reliable caregivers.

- Exploring forms of communal child-minding for older orphans whose only potential guardians are distant and who may be mature enough to live in the parental homes with siblings.

\section{Program adaptations are needed in recognition of the fact that some HIV-positive parents are also guardians and that some standby guardians are also HIV-positive or in poor health.}

Researchers and program implementers learned that many individuals fall into more than one "category" (e.g., HIV-positive parent, standby guardian, orphan). This phenomenon was not anticipated in the SP program and requires adaptations. For example, SP must:

- Support parents in planning not only for their biological children but also their other young dependents.

- Ensure that parents and guardians get the health care they need to prolong their lives.

- Assist parents in identifying guardians who are in good health if possible.

\section{The will writing component of the program was the most challenging since it defies tradition and requires the most work.}

It was difficult to find local organizations with the technical skills to train community members in legal issues. Nonetheless, property grabbing, which seriously threatens the survival of widows and orphans, remains widespread and must be addressed. There is need for:

- More intensive training and support to HIV-positive parents wishing to write a will, especially for parents with minimal literacy.

- Far greater involvement of local leaders and law enforcement personnel in upholding property rights both in the absence and in the presence of wills, especially when the heirs are young. 
- Community sensitization about property rights, as well as expansion of legal training and literacy to the entire community so that will writing does not become indelibly associated with death and AIDS.

- Exploration of alternative formats for wills or alternative approaches to reducing property grabbing that may be more acceptable and feasible locally.

\section{Material support and income-generation activities should be expanded.}

At baseline, study participants explained that what they most needed was income and/or material support for food, school, and other basic necessities. Some parents in the SP program were offered agricultural or income-generation training, but most did not receive seed funds. There is room to expand this to standby guardians. Collaborative income-generating projects involving HIV-positive parents, children, and standby guardians would allow for bonding between children and future guardians and would provide the guardian with an ongoing source of income and thus an incentive and means to take care of the children in the future.

\section{Longitudinal research is needed to better understand the long-term impact of succession planning on AIDS-affected children.}

The ultimate objective of succession planning is to improve the long-term well-being of children whose parents are HIV-positive (and could be extended to children of parents with other terminal illnesses or conditions). Therefore, the most rigorous way to test program success would be through longitudinal research following children in the program over time, through the death of their parents and well beyond.

\section{Although the emphasis on promoting the long-term well-being of AIDS-affected children is appropriate, the program may need to pay additional attention to their immediate needs.}

Even after two years of programming, many of the children in the program areas reported, for example, not having enough to eat on a regular basis. Succession planning is, again, focused on the future well-being of AIDS-affected children. But the fact that succession planning had minimal effect on the current well-being of children raises questions about whether the program should place greater emphasis on the immediate needs of children.

\section{An Update from the Field}

The implementing partners have already taken steps to strengthen succession planning.

Since the study was completed, Plan began to work with a new partner, the Association of Uganda Women Lawyers - FIDA, to enhance legal assistance in the context of succession planning. Legal 


\section{Hgrizons}

awareness-raising activities have been expanded to the larger communities. Legal services are also being offered in conjunction with HIV testing and counseling services. FIDA has also been representing SP clients in court and succeeded in recovering property. The involvement of FIDA has also been associated with an increasing participation of men in will writing.

Plan and FIDA have also recognized the importance of birth registration in protecting the rights of all children, but especially those who are orphaned and vulnerable. Without a birth certificate, a person does not legally exist or have legal access to privileges and protection of the state, including access to inheritance. Therefore, they have added support to the government's efforts to scale up birth and death registration as a component of all of their programs, including succession planning.

Plan program managers also report that parents in SP are increasingly turning to non-relatives as standby guardians, due to the shortage of able, local, and related guardians in the communities. In many cases, they have appointed counseling aides as guardians. From the children's point of view, this is probably a positive development, because it means the children need not be uprooted or stay with someone unknown to them when the parent dies. It does, however, raise concerns about the burden being taken on by counseling aides.

\section{Utilization of Research Results to Date}

This research put a spotlight on succession planning as a program approach. Once baseline findings were released, shedding light on the demand and need for future planning, many groups became interested in promoting and experimenting with the approach. Among other things, the baseline findings highlighted the value to AIDS-affected families of prolonging the parent-child relationship, promoting adult-to-child communication, and planning ahead for the child's future. The Hope for African Children Initiative and other groups have embraced these as fundamental values and priorities in programming for orphans and vulnerable children.

The succession planning approach used in this study is listed in a document prepared by UNICEF and others as one of the key principles to guide programming for orphans and vulnerable children. It also appears as a "Best Practice" on the UNAIDS website with the Horizons research report listed as the source, and appears in "Success Stories: HIV/AIDS" on the USAID website. SafAIDS is currently developing a toolkit on succession planning.

The baseline report from this study, "Making a Difference for Children Affected by AIDS: Baseline Findings from Operations Research in Uganda" (Gilborn et al. 2001), has been widely cited in key documents concerning programming for AIDS-affected children produced by the government of Uganda, the International HIV/AIDS Alliance, Save the Children, UNICEF, and the University of California at San Francisco AIDS Research Institute. 


\section{References}

Ainsworth, Martha and Innocent Semali. 2000. "The impact of adult deaths on children's health in Northwestern Tanzania," Policy Research Working Paper 2266. Washington: World Bank, Development Research Group.

AHRTAG. 1997. "Caring with confidence: Practical information for health workers who prevent and treat HIV infection in children," AHRTAG Briefing Paper. London: AHRTAG.

Bang, Sook. 1968. A Comparative Study of the Effectiveness of a Family Planning Program in Rural Korea. Doctoral dissertation, School of Public Health, University of Michigan.

Foster, G. et al. 1995. "Orphan prevalence and extended family care in a peri-urban community in Zimbabwe," AIDS Care 7(1): 3-17.

Foster, G. et al. 1997. "Factors leading to the establishment of child-headed households: The case of Zimbabwe," Health Transition Review 7 (Suppl): 155-68.

Gilborn, Laelia et al. 2001. "Making a difference for children affected by AIDS: Baseline findings from operations research in Uganda," Horizons Baseline Report. Washington: Horizons.

Green, Lawrence et al. 1972. "The Dacca family planning experiment," Pacific Health Education Reports. No. 3. Berkeley: School of Public Health, University of California.

Haworth, A. and K. Kalumba. 1991. "Social consequences of AIDS in 49 Zambian families: A descriptive study." Paper presented at the VII International Conference on AIDS, Florence, Italy, 16-21 June.

Hovland, Carl I. 1949. In Arthur Lumsdaine and F.D. Sheffield (eds.), Experiments in Mass Communication. New York: John Wiley and Sons.

Hunter, Susan and John Williamson. 1997. "Children on the brink: Strategies to support HIV/AIDS.” Washington: USAID.

Lindblade, Kim A. et al. 2003. "Health and nutritional stays of orphans under 6 years old cared for by relatives in Western Kenya," Tropical Medicine and International Health, 8(1): 67-72.

Monk, Neil. 2000. "Orphans of the HIV/AIDS pandemic: A study of orphaned children and their households in Luwero District, Uganda." Unpublished research commissioned by the Association François-Xavier Bagnoud.

Muller, O. and N. Abbas. 1990. "The impact of AIDS mortality on children's education in Kampala," AIDS Care (2)1: 77-80. 


\section{Hgrizons}

Reid, Elizabeth. 1993. "Children in families affected by the HIV epidemic: A strategic approach," Issues Paper \#313. HIV and Development Program, United Nations Development Program. New York: UNDP.

Shuey, Dean et al. 1996. "A community-based program for orphans and vulnerable children, Luwero district, Uganda: Strategies for implementation," in J.M. Mann and D.J.M. Tarantola (eds.), AIDS in the World. New York: Oxford Press, pp. 283-285.

UNAIDS. 1999. "Children and HIV/AIDS," UNAIDS Briefing Paper. Geneva: UNAIDS.

UNAIDS, UNICEF, and USAID. 2002. "Children on the brink 2002: A joint report on orphan estimates and program strategies." Washington: TvT Associates.

Wakhweya, Angela et al. 2002. "Situation analysis of orphans in Uganda. Orphans and their households: Caring for the future- today." Kampala: Government of Uganda Ministry of Gender, Labour, and Social Development and the Uganda AIDS Commission. 


\section{Hgrizons}

Horizons is a global operations research program designed to:

- Identify and test strategies to improve HIVIAIDS prevention, treatment, and care programs and services.

- Disseminate best practices and promote research utilization with a view toward scaling up successful interventions.

\section{(1) Population Council}

Horizons is implemented by the

Population Council in collaboration with

- International Center for Research on Women (ICRW)

- International HIVIAIDS Alliance

- Program for Appropriate Technology in Health (PATH)

- Tulane University

- Family Health Intemational (FHI)

- Johns Hopkins University

For more information, please contact:

Horizons Program, Communications Unit 4301 Connecticut Avenue, NW Suite 280 Washington, DC 20008 USA

Tel: 202-237-9400

Fax: 202-237-8410

Email: horizons @pcodc.org www.popcouncil.org/horizons 